Florida International University FIU Digital Commons

FIU Electronic Theses and Dissertations

University Graduate School

3-29-1999

\title{
Matrifocality and child shifting among the low income earners in Jamaica
}

Velmarie L. Albertini

Florida International University

DOI: $10.25148 /$ etd.FI13101563

Follow this and additional works at: https://digitalcommons.fiu.edu/etd

Part of the Latin American Studies Commons, and the Political Economy Commons

\section{Recommended Citation}

Albertini, Velmarie L., "Matrifocality and child shifting among the low income earners in Jamaica" (1999). FIU Electronic Theses and Dissertations. 1189.

https://digitalcommons.fiu.edu/etd/1189

This work is brought to you for free and open access by the University Graduate School at FIU Digital Commons. It has been accepted for inclusion in FIU Electronic Theses and Dissertations by an authorized administrator of FIU Digital Commons. For more information, please contact dcc@fiu.edu. 
FLORIDA INTERNATIONAL UNIVERSITY

Miami, Florida

\section{MATRIFOCALITY AND CHILD SHIFTING AMONG \\ THE LOW INCOME EARNERS IN JAMAICA}

A thesis submitted in partial fulfillment of the requirements for the degree of

MASTER OF ARTS

in

COMPARATIVE SOCIOLOGY

by

Velmarie L. Albertini

1999 
To: Dean Arthur W. Herriott College of Arts and Sciences

This thesis, written by Velmarie L. Albertini, and entitled Matrifocality and Child Shifting among the Low Income Earners in Jamaica, having been approved in respect to style and intellectual content, is referred to you for judgement.

We have read this thesis and recommend that it be approved.

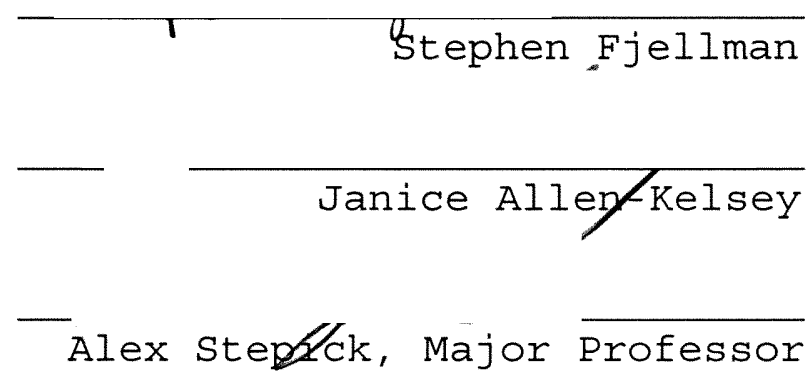

Date of Defense: Monday, March 29, 1999

This thesis of Velmarie L. Albertini is approved.

Dean Arthur w. Herriott
College of Arts and Ffiences

Dean Richard L. dampbell
Division of Graduate Studies

Florida International University, 1999 


\section{DEDICATION}

I dedicate this thesis to my husband Guy Albertini, who with love and support inspired me to complete the work, to my children, Kevin and Krysten, whose laughter completes my life, in deep appreciation to my beloved mother Petulind Blake and in loving memory to my father, James Blake. I give glory to God as ultimate source. 


\section{ACKNOWLEDGMENTS}

I wish to express my gratitude and deepest appreciation to the committee that guided this study. I am thankful for all the assistance I received from Dr. Alex Stepick, who chaired the committee and provided expertise concerning immigrant families. I am indebted to Dr. Steve Fjellman for sharing his expertise in cultural anthropology, and for conveying his belief in my potential. I wish to say thanks to Dr. Janice Allen-Kelsey for her contribution in the area of gender and family and all her encouragement. 
ABSTRACT OF THE THESIS

\section{MATRIFOCALITY AND CHILD SHIFTING AMONG \\ THE LOW INCOME EARNERS IN JAMAICA \\ by}

Velmarie L. Albertini

Florida International University, 1999

Miami, Florida

Professor Alex Stepick, Major Professor

Jamaican family structures have long felt the impact of unstable internal economic conditions and high volume of labor demands originating from England, Canada, the United States, and other larger societies. In response to the economic conditions and labor demands, increasing numbers of Jamaican women have migrated away from home, both within Jamaica and to other countries. Subsequently, many Jamaicans' households are restructured using a method called child shifting. This refers to "the relocation of children between households." Using three major theoretical paradigms: cultural diffusion, social pathology, and structural functionalism, this study explores the literature of child shifting to understand how economic conditions influence matrifocal families and in particular their child rearing practices. 
This study employs the structural functionalism paradigm's focus on "adaptive responses" to find plausible explanations for child shifting patterns. The primary premise of the "adaptive responses" approach is that economic marginality leads to certain adaptive responses in residential, kinship, and child rearing patterns.

This study finds certain adjustment problems associated with child shifting. These include shifted children developing feelings of abandonment, of anxiety, of loss, and having difficulty trusting after the shifting occurs. These costs may outweigh the benefits of child shifting. 


\section{TABLE OF CONTENTS}

CHAPTER

PAGE

I. INTRODUCTION AND BACKGROUND $\ldots \ldots \ldots \ldots \ldots \ldots$

Child Shifting and other Means of Survival........ Psychological and Social Consequences...........10 Rationale of This study...................

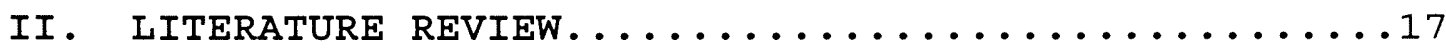

Theoretical Paradigms and the Jamaican Family....17 Child shifting as a Major Concern for Matrifocal Families............................

Economic and other Factors Leading to Child

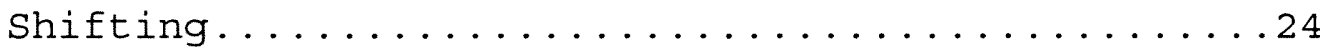
Waves of Migration and Breakdowns in Kin Group Functioning ....................... 27

III. MATRIFOCAL FAMILY AND CHILD SHIFTING WITHIN THEORETICAL PARADIGMS..................... The Cultural Diffusion Paradigm..............32 The Social Pathology Paradigm..............34 The Structural Functionalism ................ "Adaptive Responses" Approach...........37

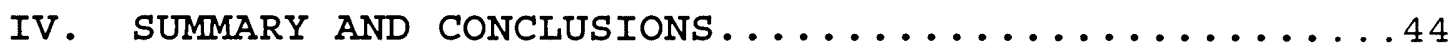

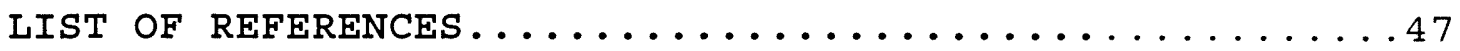


CHAPTER I.

INTRODUCTION AND BACKGROUND

\section{Child Shifting and Other Means of Survival}

By sharing the cost and benefits of child rearing, children in Jamaica are frequently moved from households that are less financially secure to others where there are more economic resources. Low-income earning households' sizes and compositions are therefore controlled by balancing and managing dependency in relation to resources. There is therefore a relationship between flexibility in household composition and economic survival, especially through migration. This is perceived by some as not only complementary but necessary. (Gordon 1987:422)

My grandmother raised me for the first twelve years of my life. Although thoughts of my childhood bring back many pleasant memories there were times of great difficulties. It was during those times that I would go to the hill, far away from my grandmother's house and shed tears as I wondered about the whereabouts of my parents. My thoughts were most often about my mother. I did not understand why they allowed the other children to remain at home while they rejected me (as it seemed to me then). Alone with my thoughts I justified my situation by convincing myself that I was a failed adoption case. That was the reason I was not worthy to live with them. During my early teens I decided it was time to take charge of my own life. However, a decision was made to alleviate my grandmother of the troubles involved in caring for me. So as a rebellious teenager I was sent to live with the parents I hardly knew. By then I resented everyone but my grandmother. She was the only mother I knew. The transition into my parent's home was very difficult. Over the years I had developed feelings 
of resentment. Besides it was now my turn to reject them. Forming an emotional wall, I refused to allow them to "break" me. It was not until I joined a local church that I began to learn to deal with some of my innermost feelings.

(Patricia 1998)

Patricia is a Jamaican immigrant who resides in the United states. In the above story she is reflecting upon the child rearing practice that senior(1991) refers to as child shifting, or making a change in a dependent child's residence or in his or her primary caregiver for extended periods. Gordon(1987)described the practice as widespread fosterage involving the relocation of minor children to households away from natural parents who may face harsh economic conditions. Using three major theoretical

paradigms: cultural diffusion, social pathology, and structural functionalism, this study explores the literature of child shifting to understand how economic conditions influence matrifocal families (women-headed families) and in particular their child rearing practices.

This study employs the structural functional paradigm's focus on "adaptive responses" to find plausible explanations for child shifting patterns. The primary premise of the "adaptive responses" approach is that economic marginality leads to certain adaptive responses in residential, kinship, and child rearing patterns. Unlike 
formal adoption that involves breakage in parent-child bond and legal sanctioning by private or government agencies, child shifting among kin in Jamaica does not include state or government involvement or monitoring(Whitehead 1978; Kerr 1962). For those reasons formal adoption is different and is not to be misconstrued as child shifting.

Gordon (1987) shows in a study of Antigua that "informal child fosterage" is practiced throughout the Caribbean (p.106). Gordon (1996)later made a distinction between three types of child shifting situations. There is "historical child shifting," involving the reporting of the childhood experience by adult respondents in the sample (p.107). There is also the case of the "current incoming child," who is currently being fostered and is included in the data (p.107). Then there are the "current outgoing children" of the respondents who reported having minor children that were living with relatives and in other households (p: 107).

Gordon's (1996) and Roberts and Sinclair's (1978) studies suggest that low-income families primarily use child shifting. For example, in 41 cases of child shifting, spread over 21 households and representing 42.9 percent of the cases, Gordon confirms that:

The reasons that children are moved from one household to another are varied and include 
singular events, in particular migration of a natural parent, as well as other abiding conditions that prompt child shifting because the child wanted to relocate or the receiving adult requested the child (Gordon 1987:437).

As a child rearing practice child shifting is not unique to the Caribbean nor even to contemporary history. For example, an episode of child shifting has been recorded in biblical history in the story of Moses, who as a child was shifted by his mother ${ }^{1}$ from his Hebrew family's household to an Egyptian Pharaoh's household to ensure his survival (Exodus $2: 1-10$ ). In a comprehensive cross-cultural study of childcare in pre-industrial society Hewlett(1991) suggests that:

There are at least three situations in which a child may not live with his or her parents: a child may acquire a stepparent because one parent dies, or the parents divorce and the parent(s) remarries, or the child may be given to foster or adoptive parents. Fostering may last a few years or a lifetime. Nevertheless, the natural parents do not terminate their bond or concern for their child(Hewlett 1991:20).

As for Jamaica, the difference lies not in the nature of fosterage but in the precipitating events that lead to

\footnotetext{
${ }^{1}$ When the mother could hide the child no longer, she got a papyrus basket for him and coated it with tar pitch. Then she placed the child in it and put it among the reeds along the bank of the Nile. His sister stood afar off to see what would happen to him. Then Pharaoh's daughter went to the Nile to bathe. When she saw the child crying, she was sorry for him. When the child grew older Pharaoh's daughter took the child whom she drew out of the water to be her child and she named him Moses.
} 
fosterage (Roberts and Sinclair 1978). Child shifting has long been established as a feature of low-income family life in the Caribbean literature (Brodber 1975; Roberts and Sinclair 1978; Senior 1991; Russell-Brown and Griffith 1997). Most analyses of Jamaica's form of child shifting identifies it as a "survival technique" employed primarily by low-income families as a response to the persistence of unfavorable social and economic conditions (Robert and Sinclair 1978 and Gordon 1987).

In the study that included a sample of 125 Jamaican households, lower-class Jamaican women who head households are primarily the group from which children are shifted ${ }^{2}$ (Roberts and Sinclair 1978). Although the practice has been indirectly referred to in most studies of family structures that discuss the extended family or kinship system in Jamaica (see for example Patterson 1982) the term child shifting is fairly new in the literature (Gordon 1987; Gordon 1996).

Patricia referred to child shifting as boarding out children. In telling her story of child shifting Patricia spoke candidly of her efforts to rebuild the communication and relationship with her siblings in Jamaica, who, as she did, experienced multiple episodes of shifting.

${ }^{2}$ Dispersed is the term used by Roberts and Sinclair (1978). 
We each take turns telling bits and pieces about the times we were separated as children. Relating our stories to each other is like crossing a bridge to our separated lives. I spend many hours on the telephone to Jamaica talking about the past and trying to smooth over the relationship between my siblings and parents. It is not easy to reconnect the ties that were broken". (Patricia 1998)

Patricia also explained that Iiving in the U.S. her exposure to North American values and self-improvement resources, such as the Oprah Winfrey show, has influenced the blending of the two cultures. Patricia's and the other stories reflect the long-lasting impact of the childhood experience on adult-immigrants in the U.S. They are also interpreting middle class, North American values concerning child rearing as they travel and communicate with relatives in Jamaica.

The exact number of children who are shifted is not available; however, they number in the thousands. It was recently estimated that between $15 \%$ and $30 \%$ of Jamaican children are raised as shifted-children(Evans and Davies 1997). Robert and Sinclair (1978:162) reported earlier that as high as $30 \%$ of the lower-class Jamaican female respondents of childbearing age they interviewed engage in child shifting. Tables 1 and 2 below list the reasons Jamaican children are shifted and the average ages of the 
mothers of shifted children, respectively.

Most child shifting in Jamaica relates to mothers' involvement in the work force. Women between ages 20 years and 34 years are most likely to engage in child shifting (Roberts and Sinclair 1978). 
Table 1 .

Reasons given for child shifting

Reasons for child shifting

Total

Distribution Total

Mother had to work

Grandmother wants child

9.6

No support from father 3 7

2.4

Better school

Financial Problem

4

5.6

Taken away by father

Lack of space

Unable to Care for child

3.2

Other

$\underline{26}$

11.2

20.8

Total

125

100.0

Table 2 .

Age of the mothers of shifted children

Age of mother

Total

․ Distribution Total

Under 20

7

5.6

$20-24$

18

14.4

$25-29$

48

38.4

$30-34$

23

18.4

$35-39$

16

12.8

$40+$

$\underline{10.4}$

Total

125

100.0

(The tables were adopted from Roberts and Sinclair 1978: 164). 
Besides highlighting that certain economic conditions lead to child shifting, Gordon (1987)reports that shifting is accommodated by the great flexibility of the Jamaican family. Child shifting is characterized as a practice that involves the intervention of older women or women without children in raising children born to young mothers (Roberts and Sinclair 1978). According to Roberts (1975) during the mid-1970s 70-75\% of the children born in Jamaica were to younger women in non-marital unions.

Traditionally, older women would form core domestic units, that change frequently as they accommodate young daughters bearing children and then relocating from their mother's unit without the children (Roberts and Sinclair 1978). Those children would remain in the grandmothers' unit temporarily without their mother, or if necessary they may be sent to other household units such as aunts, cousins or friends while the mother leaves to seek employment or set up a separate household unit (Roberts and Sinclair 1978:161; Grant 1974).

The plan is usually for those arrangements to be temporary, but often it results in longer placements than were intended as harsh economic conditions persisted (Roberts and Sinclair 1978). A major concern raised in that study relates to the many children who shifted from low- 
income households with longer periods of separation than what is desired by even the parents themselves (Roberts and Sinclair 1978:161).

I spend my entire childhood living with my grandmother. As a matter a fact I consider her to be my real mother. When she died, I realized that although my biological mother is still alive I cannot seem to think of her as a mother. Perhaps it is because I never got along with her. The thing I regret most is the limitation of my schooling. My grandmother was not able to read nor write so she was unable give me the help I needed to excel in school. She was also a bit old timish like most people who live in the country areas (Tammy 1996).

Roberts and Sinclair (1978) also identified the flexibility in family and household units as a factor that accommodates child shifting in Jamaican society. The most common reason for child shifting in that study is "mothers had to work." The child shifting was facilitated by the grandmothers' households, which were expected and willing to accept the shifted children. The flexibility of the receiving units is illustrated in Table 3 . where $54.4 \%$ of the sample distribution were children placed in the grandmother's household. Typically shifting occurs in situations where young unmarried daughters become pregnant and give birth while residing in their mother's home (Roberts and Sinclair 1978: 21-40). After the establishment of the grandmother's 
household, usually the unmarried daughter will leave to form or join a new unit such as the common-law union. ${ }^{3}$ The common-law unions are usually less accommodating of children from prior unions and may or may not later become marriages (Roberts and Sinclair 1978: 49-67). When child shifting occurs new relationships must be developed within the extended family system. The responsibility for developing the new relationships within an already existing family unit usually falls upon the shoulders of the child(Evans and Davies 1997).

\section{Psychological and Social Consequences}

While child shifting within a Jamaican family structure may appear to some as presenting no special problem for the working-class in Jamaica, some problems relating to adjustment surfaces, when elements of these families who in response to economic forces, migrate to other countries such as the U.S. and even when interacting with middleclass Jamaicans living in nuclear families (Dechesnay 1986).

Although the treatment of shifted children may vary in Jamaica, there are many accounts of children developing feelings of abandonment, anxiety, loss, and lack of trust

${ }^{3}$ Common-law: The man and woman are maintaining a shared household with sexual union without legal sanctioning of the union. 
between parent and child after the shifting experience

(Evans and Davies 1997). The main problem related to child shifting, as Leo-Rhynie (1993) points out, is that maternal deprivation of any kind, particularly in early childhood can result in delays in social, physical, and intellectual development. Even in cases where children are shifted to close kin such as grandmothers, often the grandparent is too old and is unable to cope or cannot always provide adequate for the social and educational development of the children (Gussler 1980:197).

Although some early studies suggested the possibility that child shifting may enhance the children's ability to interact with a wide range of persons and to adjust to new social situations (see Gordon 1987, Brodber 1986), later longitudinal studies indicate that many shifted children are experiencing marginal, anxious and unstable lives (Evans and Davies 1997; Senior 1991). For example, Evans and Davies (1997) show that:

There may be great consequences of child shifting when the child is not wanted or not treated well in the household to which they are moved. The impact at different points of development affects the development of selfconfidence and self-esteem, the parent-child attachment and healthy development also illustrated by Bowlby (1969). 
In exploring the adjustment and social problems related to child shifting and youths in Jamaica, CrawfordBrown (1993) argues that child shifting may produce maladaptive behaviors and even the development of criminality among Jamaican adolescents. Using a sample of 70 adolescent males, Crawford-Brown (1993) identified the two elements that appear as the most powerful structural family factors associated with adolescent criminality as: 1) the absence of the mother in the raising of the child, and 2) frequent changes in parental living arrangements and ensuing negative role modeling.

Although the literature in this area is quite limited, numerous studies suggest a relationship between migration of a significant parent (usually the mother), and a shifted child's personality development, aggression, delinquency and violence behavior (Evans and Davies 1997; Leo-Rhynie 1993). Based on those critical issues "the child's perspective of shifting" merits greater exploration.

Since beating and cursing is still the acceptable form of discipline for many in Jamaica, you cannot trust your child with just anybody and anybody. I have scars that give me the right to say that. If a mother can manage to hold on, child shifting should be avoided at all cost. No explanation is ever enough to prepare especially a young child for such isolation and loneliness. Also who can predict the things that develop in the mind of a child if the arrangement is an unhappy one. There can be no going back to change 
childhood. Only the child can know if there is a sense of loss. I went through so much abuse at the hands of people whom they paid to take care of me-you would not believe it. Some people took the money but did not take care of me. Absent parents cannot always pick up on these things or intervene. My grandmother did not raise my mother and my mother did not raise me, but I am determined to raise my own children (Beverly 1997).

The focus of many studies, such as Gordon(1987), Robert and Sinclair(1978), and Roopnarine and Brown (1997) are on the many problems associated with unhealthy child and family development that stems from child shifting and the mistreatment of shifted children. As Hall(1979) reports, the quality of supervision and care provided by others in the absences of natural parents in Jamaica is very often considerably inadequate.

You name it and we just had to deal with it ourselves. My mother left Jamaica to work overseas in the 1970s and has traveled back and forth to this day. At first they sent me to live with my grandmother, but after she took sick my mother returned. I moved back to my mother's house but then she left again. My grandmother was still too sick to care for us, so they boarded us out in different peoples' homes. As a family we have always lived apart. I have a younger sister. She has never lived with our parents. My brothers and I talk from time to time, but one brother is very withdrawn and has not engaged much with the family since adulthood. Talking about the things we went through is difficult. Some things are very personal and even embarrassing. I suspect 
something really strange may have happened to my brother but it is not something we discussed (Pansy 1998).

Most studies that address child rearing practices in the Caribbean have not reviewed the interconnections between women's economic activities and child shifting from the adult child's perspective in a cross cultural context (Roberts and Sinclair 1978; Gordon 1987). Most of the studies that do address this issue, however, suggest that as a social response to unfavorable economic conditions the cost outweighs the benefits (Evans 1989:181-82). For example, Barrow shows, while there may be some compensation in terms of positive socialization value for children raised with "extra-family involvement," when the interrelationships are unhappy and unhealthy then insecure, unsatisfactory environments are created and the effects on the child can be very damaging (Barrow 1996:407).

Barrow (1996) also comments that the inadequate amount of data related to women's choice and child rearing is of concern because of how much influence each will pose for future development in the Jamaican society. Fifteen to thirty percent of Jamaican children are affected by child shifting. That is a significant amount. The figures suggest that there may be issues concerning child shifting that may affect the entire society. 


\section{Rationale of This study}

In examining Jamaican family structures and child rearing practices, anthropologists and other students of culture have not focused sufficient attention on the economic and migration factors. These factors appear in the literature simply as peripheral influences on family structures. Our aim is to look with greater scrutiny at how economic activities influence the migration of women away from households (Bolles 1996:2) and the effect on child rearing. We view the economic and migration factors as having great influence on family structural development at the local level.

In overlooking the above factors, some interpretations of the developing Caribbean countries have understated the economic sustenance role of women. Women are mistakenly portrayed as invisible participants, restricted to domestic routines with limited influence on the development of family and the overall social structure (Barrow 1996:156). Therefore, the aim of this study is to shed light on the strength and resiliency of low-income families that use child shifting in Jamaica, as well as to add to the knowledge base of Caribbean family structures. This study will build on the premise that "family developments do not 
occur in a socio-cultural vacuum, but are rather given shape and are continuously influenced by all members and the conditions of the society in which they exist" (Henslin 1985) .

In line with Dorian Powell's (1984:194) reports that "Jamaican women are carrying the enormous responsibility of ensuring their own, and the survival of extended family members," we explore the literature to explain how some women function as heads of households and how children cope when such family units are disrupted and maternal bonds are strained or broken (Roopnarine and Brown 1997; Barrow 1996). By identifying where empirical studies of Jamaican family structures, specifically the matrifocal form, converge and diverge, this review adds new information concerning the roles of women as decision makers and operative constructors of Jamaican family structures. No single theory explains the complexity of Jamaican family structures and child rearing patterns.

Three major theoretical paradigms that appear frequently in literature may provide the framework for exploring contemporary Jamaican family and child shifting patterns. The paradigms are cultural diffusion, social pathology, and structural functionalism with focus on the "adaptive responses" of Jamaican families. Aspects of 
child shifting, from the insiders' perspective, will be brought to the forefront by revisiting earlier studies of child shifting in the Caribbean region. It is essential to bear in mind that child shifting as it is described by Gordon (1987) is not viewed solely as a social problem. Rather, the practice is identified as a culturally derived solution to the problems associated with what Barrow (1996) refers to as Caribbean women heading households under socioeconomic circumstances of deprivation and uncertainty. 


\section{Chapter II.}

\section{REVIEW OF THE LITERATURE}

This chapter is divided into four sections. The first is a presentation of the theoretical paradigms that undergird the study. This is followed by an examination of some of the major concerns about child shifting. The third section identifies economic and other factors that lead to child shifting. The final section discusses migration patterns and breakdowns in kin group functioning in Jamaica.

\section{Theoretical Paradigms and the Jamaican Family}

Three major social science paradigms appear in the literature. Each is presented as a possible approach to understanding child rearing practices among low-income matrifocal families, (Kuhn, 1970).

The Cultural Diffusion paradigm has been used to explain the historical development of the matrifocal family form. Within this perspective matrifocal features are viewed as cultural representations of African family structures. Those ascribing to this view hold to the premise that the matrifocal family form in Jamaica is 
evidence of the retention and modification of family structures based on the particular ancestral origins of West Africans who were brought over to be slaves in Jamaica.

The Social Pathology perspective undergirds explanations that view matrifocality and even child shifting as a legacy of slavery and the middle passage. Those following this perspective say that Jamaican family structures are non-traditional and deformed or dysfunctional imitations of the European nuclear family form introduced to the African slaves by slave owners and others.

The structural Functionalism paradigm that appears later in the literature is often presented as a response to the two previous paradigms. This paradigm builds on its predecessor, the social pathology perspective. Unlike its predecessor, however, the structural functional approach sought to assess matrifocal family form by reducing the deformed and dysfunctional aspect, claiming rather that the family form develops as an adaptation to socioeconomic conditions in Jamaica. This approach seeks to explain matrifocal families as structured and as functioning in response to economic marginality and poverty rather than as pathological anomalies (Barrow 1996:68). 
In his work on the Caribbean family Rodman (1971) incorporated the notion that lower-class women are making personal choices that determine family structure and child rearing practices. This fits neatly within the "adaptive responses paradigm"(Rodman 1971: 200). The "adaptive responses" perspective may therefore be seen as an extension of the structural functionalism paradigm.

\section{Child Shifting as a Major Concern For Matrifocal Families}

In making a clear distinction between "informal"

fosterage (child shifting) and formalized adoption, Hewlett (1991) explains that child shifting, as it relates to Jamaica, does not involve legal termination of the bond between natural parents and child nor a dramatic breakage in natural parent-child interaction and relations. To examine child shifting in Jamaica, matrifocality must first be explained. Child shifting challenges are therefore better understood when the practice is viewed in the context of the matrifocal or "mother centered" household.

Smith(1956) points out in his comprehensive work on Jamaican families that unlike most societies that are patrifocal, where the man is the key decision-maker in the family, in Jamaica it appears that women play the role of key decision-makers in many lower-class families. Aside 
from the realm of decision-making, the heading of household by women is also deeply rooted in the concept of matrifocality (Gonzales 1970; Smith 1956, Barrow 1996;

Chant 1996). In his analysis of matrifocality Smith stressed that in Jamaica the bond between mother and child is the strongest in the whole matrix of the social relationships:

Such a bond endures through times as a strong reciprocal relationship thereby ensuring that the woman with children will always find ways to provide for them and the children in turn will provide for the mother in her old age. (1956:65) Fortes also emphasized that the key to understanding the Jamaican family is the knowledge of the strength of the mother-child relationship and the tendency for the unit of a woman, her children, and her daughter's children to emerge as a particularly solitary unit, that often constitutes the core of the domestic group (Fortes 1947:68). Building on Smith's (1956) description of the household, Gonzalez (1970) and Mohammed (1986) address the need for in-depth explanations of the variance in the meaning and the diverse usage of the term matrifocal.

In doing so Mohammed (1986) revisited some of the older studies of Caribbean families (Gonzalez 1970; Frazier 1939; Clarke 1957; Blake 1961; Brodber 1982) and suggested three basic features of matrifocality that are specific to Jamaica:

1) Matrifocality may imply that the women in 
Jamaican society have a rather good status, or that they may have more control over income and expenditures. 2) In another context matrifocality may refer to a situation where women are the primary earners in the household. 3) Elsewhere it may refer to households where male absenteeism leads to a predominance of women-headed households that are the nature of a great portion of matrifocality in Jamaica. (Mohammed 1986:170-182).

More recently, Macionis (1997: 459) pointed out the importance of understanding the non-traditional residence pattern of matrifocal families in Jamaica. He refers to it as the matrilocal residence, or "the place of the mother" a residential pattern by which couples live near the woman's or wife's family (p. 459). The matrifocal family unit is most often characterized as one in which an adult woman (usually with children) lives and sustains the household, with or without a live-in male partner (United Nations, $1991: 17)$.

The presence of matrifocality among low-income families in Jamaica has received much scholarly attention in the Caribbean literature (Patterson 1982). While many studies do not specifically use the term matrifocality, much focus has been on what appears to some as a "truncated" family form, characterized by the marginalization of males from household headship and the raising of children (Barrow 1996:22). "The 
corollary of male marginality is therefore often presented as matrifocality" (ibid.: 22).

The term matrifocality is also used interchangeably in the literature with other concepts such as "mother-centered family," "female-centered family," "woman-centered family," "matriarchal family," "female-headed household," or "grandmother family" (Roberts and Sinclair 1978; Gonzalez 1970.) In addition to household headship, typically Jamaican women are presented as playing the dominant role of ensuring the psychological and the economic survival of the family (Chant 1997: 29). As Powell (1984) indicates, "in Caribbean literature Jamaican women are portrayed as performing a disproportionate amount of work while shouldering the great responsibility of ensuring the basic survival of children" (p.104).

However, Jamaica is not a completely matrifocal society. Evans (1996) delineates five types of family structures in Jamaica: 1.) the marriage union, 2) the commonlaw household, 3) the visiting household (where the mother still resides in her mother's house), 4) the kinship-related household and 5) the single-parent(ibid :1996 419). Each is associated with socioeconomic and life variables, values, aspirations and norms for interacting with and raising children (ibid. 1996: 419). 
The inability of women to secure the economic resources needed to maintain an "intact" household is related to the persistence of child shifting. Focusing on the low-income family and the socioeconomic variables, Stolcke, (1992) suggests that:

Although the mother-child dyad in Jamaica is the ultimate (biologically) irreducible core of the family and women assume household and child care responsibilities under harsh economic conditions, there is nothing "natural" or inevitable about the feminization of household headship under poverty.

Reviewing this premise, "there is nothing 'natural' or inevitable about the feminization of household headship under poverty" (ibid.: 1992) we find that Stolcke's(1992) argument may be suitable for exploring how and why shifting is used by the matrifocal family in Jamaica.

In revisiting some of the concerns about shifting raised in the works of Roberts and Sinclair (1978) and Gordon (1996) we find that:

"A dominant feature of the Jamaican family that remains is the frequency with which women, especially those not formally married and living under harsh economic conditions, send their children away to others better able to care for them." (Robert and Sinclair $1978: 161$ )

Roberts and Sinclair (1978)raised concerns about the length of the separation of shifted children from mothers especially when the separations take place during crucial 
formative years. There were also concerns over the confinement of shifted children to rural environments during formative years and the conditions under which children are removed from their parents' homes (Roberts and Sinclair 1978:162; Evans 1989: 176-99).

Other earlier studies of low-income earners in Jamaica suggested that the bond between mothers and children was expected to endure during long term separation (Smith 1965), but those findings are challenged by data reflecting severe impact on parent-child and family development(Evans, 1996, Leo-Rhynie 1997). Studies looking specifically at the loss of interaction and communication between mothers and their children suggest that factors such as parental migration affect not only the child's development but may lead to criminality among adolescents and other challenges for law enforcement agencies(Evans 1989:183-84, CrawfordBrown 1997).

\section{Economic and Other Factors Leading to Child Shifting}

While a high status is placed on the "mother role" in Jamaica as a rite of passage into adulthood, these beliefs often propel young men and women into early childbearing long before they are financially, emotionally, or developmentally ready 
for parental responsibilities. Although for the parents such early onsets of pregnancy may contribute to feelings of positive self-image and self-worth, it may have long term effects on the process of socialization. Furthermore, the young woman and her children may become trapped in a cycle of child-rearing, low-paying jobs and poverty (Durant-Gonzales 1982).

Many questions remain as to why child shifting appears so frequently among low-income earners, while it is far less common in higher income sectors(Patterson 1982, Roberts and Sinclair 1978). Some anthropologists suggest that the rate at which low-income households develop and restructure themselves relates to conditions of economic duress (Fortes 1947). It has been shown that child shifting occurs most frequently in families from which fathers, as well as their economic contributions, are absent (Chant 1997). When women are left in the position of sole economic and nurture providers they continuously alter household sizes to maximize the limited resources (Roberts and Sinclair 1978; Gordon 1996). This factor relates to broader socioeconomic issues.

In illustrating the great disparity in the distribution of economic resources in Jamaica, that is based on class and gender stratification, Sobo (1996) shows that approximately 85\% of Jamaica's population consists of 
the poor working class. The overall per capita income of the average Jamaican in 1987 totals to less than U.S. \$1000 annually (ibid.: 1996:496). Reporting further on the disparity in terms of economics and gender, sobo indicates that in 1987 the unemployment rate for women, at 29.5\%, was twice that of the men's 13.6\% (1996:496).

Those figures reflect hardship for many, but particularly for women and, we assume, children. With a high unemployment rate combined with the low wages of women in the prime child bearing years under age 35 years old (STATIN, 1988) household restructuring using child shifting is an option many are forced to choose. In addition to income, the age of the parents is a factor that influences shifting. According to Roberts and Sinclair (1978), women between the ages of 25 years and 29 years practice child shifting on a substantial scale. The age-related factor of child shifting is depicted in $38.4 \%$ of the sample distribution. An average of $18.4 \div$ of the women in the 30 to 34 years age groups used shifting (Tables 1 and 2). Leo-Rhynie (1993) documents that in $1984,28 \%$ of all the children born in Jamaica were born in conditions of poverty to women 16 years of age or younger. Among women aged 17-24 years the unemployment rate averages at $60 \%$ (Ennew and Young 1981). Although there is a high demand 
for female labor, specifically in the service and exportprocessing sectors, the jobs available to women in Jamaica are usually far away from their rural communities and low paying. Women's migration from rural to urban areas has increased steadily over the years. Migration therefore contributes to child shifting(Bolles 1996: 61-95; Safa $1995: 3)$.

In response to the question, "why do women in the lowincome sectors and not those in the higher-income sectors tend to use shifting?" Roberts and Sinclair's (1978) findings, suggest that the women least likely to practice child shifting are generally those under twenty years of age and those in the higher income earning sectors. Accordingly, women below the age of twenty years in Jamaica are less likely to be employed and more likely to be still considered as dependents of another adult (ibid.: 1978).

Table 1 (on p. 7) illustrates that low-income earning women ranging from ages 20 years to 39 years $184 \%$ of Roberts and Sinclair's sample), were most likely to practice child shifting. Unlike the younger and lowerincome earning women, those who are in the higher income earning sectors may possess the economic means of supporting their households without resorting to child shifting(Roberts and Sinclair 1978). Also the upper strata 
have fewer matrifocal units, and the presence of adult males in the household may increase economic resources, thereby downplaying the need for child shifting.

Those in the middle class are employed in skilled, highly skilled, professional, or managerial occupations and normally choose to marry. The low-income groups, who are mainly unskilled, semiskilled, or unemployed, choose common-law or visiting unions or live in a kinship-related household. Because marriage is considered the ideal form of union, many marry after childbearing is over. Given this typology of family development it often happens that the mother has to leave her child with others. (Evans 1989: 178)

For those reasons, child shifting is less common among the population Roberts and Sinclair (1978) refers to as the upper class.

Waves of Migration and Breakdowns in Kin Group Functioning

The literature shows a direct connection between migration and child shifting as, first, parents' migration, and second, the request for children as companions and helpers by grandparents (Gordon 1987). The primary factor influencing decisions to migrate, and subsequently to shift children as households restructure, is employment opportunities in the urban areas and overseas(Roberts and Sinclair 1978; Gordon 1996). 
Recent studies show a pattern of families continuously using migration and household restructuring as a means of economic survival (Bolles 1996:61-95; Safa 1995). Reporting on changes in the family, Brodber(1975)argues that structural changes in contemporary Jamaican families resulted from the waves of Jamaican migration. There have also been noticeable breakdowns in kin group functioning especially among low-income earners. An example of the impact of migration on families is that raising children in Kingston, Jamaica, whether by kin or others, is frequently done outside the mother's household (Bolles 1996:10). The option some women choose is to send children to friends or kin whose household is in the countryside (ibid., p. 11). Barrow (1996) argues that there is a historical relationship between changes in contemporary family structure and the wave of male migration of the 1950s. Barrow (1996) further holds that Jamaican families are affected by the large numbers of Jamaican fathers who immigrated at the turn of the 19th century and the persistence of the marginalization of males from the labor force in Jamaica(ibid., p. 171).

There is far reaching impact due to the mass emigration of Jamaican males (fathers)to foreign places, such as Panama to work on the canal, Cuba to cut cane, and 
the United States, Canada and England. Over a short period of only about four decades migrating males left literally thousands of mothers, grandmothers, sisters, daughters, aunts, nieces, and female cousins to assume roles of sole provider(Patterson 1982; Barrow 1996). The later migration of the women left behind featured women's moves from rural to urban areas in search of employment (Roberts and Sinclair 1978:8). As the women moved to areas such as Kingston, many developed other conjugal relationships, and had children which they later sent "home" to the country to be raised by grandmothers (ibid., 161-174 also see Gordon 1987:428 and Barrow 1996).

Following the male emigration during the twentieth century, many changes were enacted in immigration policies of outside countries that triggered another large scale exodus that reflected Jamaican women as the primary group that emigrates from Jamaica(Barrow 1996). It became even more common to find grandmothers in Jamaica raising a second generation of children in the absence of the parents (Barrow 1996). That pattern is also illustrated in Table 3 below. 
Table 3 .

Persons caring for children that are shifted

Person caring

for the child

Maternal

Total 을 Distribution Total

grandmother

Paternal

grandmother

Father

Aunt

Other

68

13

24

11

$\underline{9}$

125
54.4

10.4

19.2

8.8

$\underline{7.2}$

100.0

Total

(This table was adopted from Roberts and Sinclair 1978: 164).

Brodber(1982) suggests that mass migration and subsequent changes in family structures resulted in a severe shortage of kin willing and available to raise shifted children. The steady reduction in the availability of suitable kin to care for shifted children led to increases in the use of non-kin"child-minders"4 (ibid.: 1982) and child care problems. As a result of breakdowns in kin group functioning child shifting is no longer viewed solely in the context of Caribbean family and household flexibility.

${ }^{4} \mathrm{~A}$ person who is paid to accept and raise children from someone else's household. 
CHAPTER III.

\section{MATRIFOCAL FAMILY AND CHILD SHIFTING WITHIN DIFFERENT THEORETICAL PARADIGMS}

This chapter discusses the literature on matrifocal families and child shifting situations within a theoretical context. The literature presents Jamaica as similar to most societies in that the expectation remains that the family serves as the primary socialization agent or social institution that unites individuals into cooperative groups that oversee the bearing and raising of children(Macionis 1997). However, in reviewing some earlier studies of the Jamaican working class, Bolles (1996) points out that beginning around the 1940s the foci of most anthropological studies of the Caribbean family emphasized household organization and mating patterns within cultures where extramarital mating, the acceptance of birth outside wedlock, and high incidence of female-headed households appeared as normative experiences.

Bolles identifies three main figures, Murdock (1949), Parsons (1955), and Fortes (1943), as leaders in declaring the primacy of the nuclear family model as the most rational functioning family, favored with specific juridical and political domains and rights and prescribed 
gender roles (Bolles 1996:6). European missionary and clergy further reinforced those beliefs, in interpretations of Jamaican families (ibid. 1996). Accordingly, these earlier studies also presented Jamaican family structures as inherently unstable or pathologically deviating from the traditional European nuclear family(Bolles, 1996:101). Most contemporary studies have challenged aspects of the earlier studies completed during the periods when the interpreters of Jamaican culture were predominantly cultural outsiders (Brereton 1988: p. 142).

\section{Cultural Diffusion Paradigm}

Herskovits (1941) is identified by many scholars as the greatest proponent of the cultural diffusion approach. He argues that the matrifocal family form with maternal and extended family features is a contemporary representation of West African tradition.

Several family characteristics, including the looseness of the conjugal bond, the nucleus of mother and child, the importance of family support to the individual, the peripheral status of the father and the rituals of courting, birth and child socialization, are not pathological manifestations of the European family, but constitutes retention and subsequent reinterpretations of African customs (Herskovits and Herskovits 1947:296; Barrow 1996:5). 
Despite the enormous historical contribution of his work, Herskovits'views were widely rejected during the 1950s and 1960s. It is only recently that many sociologists are revisiting the cultural diffusion perspective and recognizing its place in the literature (Smith 1982:119121). The main focus of the controversy surrounding Herskovits' work is his premise that the experience of slavery did not cause the maternal family, as claimed in the more widely accepted work of Frazier (1939).

Herskovits claimed instead that matrifocal households develop because of culturally endowed characteristics preserved and transported by the Africans to the Caribbean (1941:181). Even with the resurgence of interest in the cultural diffusion perspective, some still question the extent to which African origins played, or continue to play, a vital role in family development in contemporary Jamaica (Patterson, 1973:159-70; Besson 1993:21). Herskovits argued that in places such as Jamaica, diminished forms of Africanism have persisted(1958:139). Accordingly, Herskovits developed a "scale of intensity of Africanism" to measure degrees of Africanism within Caribbean cultures (Barrow 1996:4). Herskovits could not totally dismiss the influence of slavery in relation to Jamaica(Barrow 1996:4). In the English-speaking region, 
which includes Jamaica, Herskovits (1958:139)proposed that the plantation system may have rendered the survival of certain African family types impossible. It undermined the underlying moral and supernatural sanctions, although they may still exist if only in diluted forms. Slavery, he argued, may have suppressed most of African family life, leaving only rough approximations of certain forms of Africanism (ibid.: 1958:139).

The cultural diffusion argument is also challenged by evidence that the nuclear family form existed to some degree among the slaves, and that matrifocal households were rare (Barrow 1988: p.159). Patterson and others used the dominance of the nuclear family form among the upper strata in Jamaica as evidence to argue that matrifocality is based more on economic conditions than the African origins proposed by Herskovits (Patterson 1982). "Since some slaves, in fact, transformed the European institution to legitimize conjugal commitments of older slaves who were past child bearing years, that this move of the African toward Eurocentric respectability later was seen among the contemporary middle to upper strata in Jamaica (Besson 1993:21).

Despite the many oppositions to the African origin premise, Herskovits holds a very strong position in the literature with one of the firmest arguments against the explanations 
put forth earlier by Frazier (1939) who is discussed the following section.

\section{The Social Pathology Paradigm}

Within the social pathology perspective, Simey, a colonial social advisor from England to Jamaica, and M. G. Smith emerge as key figures in the investigation of Jamaican family structures (Barrow 1996:8). This perspective seeks not to provide theoretical explanations but rather to assess and radically change the Caribbean family structures viewed as social problems and potential threats to the European-nuclear family traditions (ibid.:1996:9). The main premise of this perspective is that Jamaican family life is shaped not so much by Africa as Herskovits proposed, but rather by elements such as the history of slavery, emancipation, and the oppression that erased most of the African cultural influence. This produced a failure of the lower class family to meet expected Christian standards (Smith 1957; Simey 1946; Frazier 1939).

Although the social pathology perspective was rejected by many, some scholars continue to present the argument that it is the slavery heritage that has resulted in the 
development of family patterns presumed to be socially dysfunctional and falling short in measuring up to the ideals of the nuclear family form (Kardiner and oversey (1951). This was also the view of M.G. Smith (1957) Simey 1946) and Frazier (1939). Frazier (1939) gained much credibility in arguing that the system of slavery was not conducive to the continuation of African family form, as those subscribing to that view had claimed. The conditions of slavery, he and others therefore claim, precluded the development of stable nuclear families (Frazier 1939; Henriques 1953).

The shortcoming of this approach lies in its failure to assess that which Smith (1961) and Cumper (1961) illustrate as a positive relationship between local employment opportunity and stable households in the West Indies. Even in combining the cultural diffusion and social pathology paradigms we find insufficient evidence to support the exclusion of the economic and migration factors that have influenced family structure and child rearing patterns in Jamaica (Barrow 1996). The long debate that ensued on Herskovits' perspective versus Frazier's perspective has done more to enrich the literature with the wealth of socio-cultural information than to explain patterns such as matrifocality (Mintz and Price 1976: 43) 
or child shifting in contemporary society.

\section{The structural Functionalism Paradigm with an "Adaptive Responses" Approach}

The structural functionalism paradigm as it relates to Jamaican families was introduced in the early 1950s (Barrow 1996:11). This perspective relies on assumptions made popular by anthropologists such as Malinowski (1944; 1945), and Radcliffe-Brown (1965) and the sociologist Parsons (1951). Essentially, this perspective seeks to understand how the interrelated parts of the family system function to meet the needs of the lower-class family. Many Britishtrained anthropologists have used the structural functional approach to describe family structures in Jamaica (Clarke 1957; Henriques 1953; Smith 1956).

Within the structural functional perspective, the matrifocal family form is viewed as a functional response to the disorganizing effects of contemporary economic disparity based on class and gender (Barrow 1988:160). As more scholars move away from the traditional nuclear family model, subscribing less to pathology and more to functional models, increasing interpretations have surfaced to illustrate that Jamaican family forms are not dysfunctional 
but rather useful adaptations to economic marginality (Whitten and Szwed 1970; Chant 1997; Patterson 1982; Barrow $1988: 162)$.

Clarke(1966) argues for example, that matrifocal family forms and its child shifting patterns develop in societies in which the following circumstances are present: poor socioeconomic conditions; an absence of land holding for consistency in patrilineal and matrilineal practices; loose sanctions against illegitimacy and a tendency toward nonlegal marriages; and the presence of readily available kinship and community support for a network of child rearing, as with Jamaica.

\section{"Adaptive Responses" Approach}

In a study of matrifocality, Gonzales (1970) concluded that the element of women choosing to form matrifocal families is explained by an "adaptive responses" approach. In Jamaica, when the presence of unemployed conjugal males restricts or compromises women's potential to maintain supportive relationships with consanguine (blood relatives) and other males, matrifocal units are formed (ibid: 1970; Prior 1993). Based on cross-cultural data on society's modes of production and political economy Blumberg and 
Garcia (1977) conclude that environmental uncertainty and scarce resources lead to specific "adaptive responses" in residential and kinship dynamics.

That model was found to be very effective in analyzing Jamaican household flexibility and residential composition (Whitehead 1978: 817). Whitehead (1978) presents a 13-month ethnographic study of Haversham, an urbanizing Jamaican community just outside Kingston, which he identified as a microcosm of the larger Jamaican society. Using both structured and semi-structured procedures he interviewed three groups: 1) samples of males and females in 238 households; 2) 80 males representing various social categories including different age, ethnicity, and socioeconomic status; and 3) 20 females who were the mates of males in the sample (ibid.:1978:819).

Whitehead(1978:824) identified survival strategies, such as female-headed (matrifocal) households (41\%), as well as the restructuring of household size and composition as a primary feature of low-income earners. The study confirmed the applicability of Blumberg and Garcia's theory that links mode of production and economy to both family and household structure in Jamaica. Whitehead(1978) confirms that dependent children in the Haversham's 
households, particularly young children, are frequently moved out to other households, mostly grandmothers' (ibid.: $1978: 824-25)$.

Such emergence and endurance of female-headed households are linked to the society's mode of production, and political economy as indicated by Blumberg's and Garcia's (1977) work that attempts to flag conditions that might lead to the formation of mother households in capitalistic societies (Chant 1997:32.)

In Jamaica where, for example, $45 \%$ of the population in Kingston lived in female-headed households (Safa and Antrobus 1992:70), Stolcke suggests that social and ideological constructions of gender have also shaped the ways in which people have tried to deal with economic crisis, and they have been affected by its outcome (ibid.: 1992:138). In line with the "adaptive responses" school of thought, household restructuring and child shifting serves a natural function (Chant 1997:100). Blumberg and Garcia (1977) and other feminist scholars who explore the connections between the persistence of matrifocality and child shifting in societies such as Jamaica review basic conditions that are paramount for the development of matrifocal households and child rearing patterns. Chant (1997) for example, provides some basic interpretations of the conditions showing that in most societies where men 
hold the assets in household groups and production is a collective enterprise, it is less likely that women will secure the necessary resources to determine their household structure.

So it is the independent access to jobs in Jamaica that enables women to head separate households (Chant 1997). In addition, for women who serve as primary providers it is necessary for the means to be available to reconcile employment opportunities with childcare needs (Blumberg and Garcia 1977:109). Jamaica's extended kinship system traditionally has allowed children to move between households and thus reconcile the dual role of mothers as income earners and childcare providers (Chant 1997:46).

Chant(1997) cautions that while Blumberg and Garcia's (1977) model is helpful in identifying economic and structural factors that influence the formation of matrifocal households, there are some major drawbacks to focusing only on market economies. Chant disagrees, for example, with Blumberg and Garcia's dismissal of the "cost" of children as too blunt a usage of their model (Chant 1997: 33). Whitehead (1978: 825) also warns against totally ignoring the historical significance of the cultural 
diffusion, social pathology, and some aspects of the structural functionalism models. He offers support for more careful application of the "adaptive responses" model in analyzing matrifocal families and child shifting practices in Jamaica.

An overwhelming majority of the children from the lowincome group are raised in matrifocal households that develop and restructure prior to marriage (Evans, 1996 419). In Barrow's (1996) support for the "adaptive responses" approach as a plausible explanation of how Jamaican families function, it is noted that many misconceptions remain about the use of the nuclear family as the only criterion by which the matrifocal family patterns should be evaluated (Barrow 1988:160; Smith $1971: 231-32$ ).

Our contention is that the Herskovitses for example fail to analyze the contemporary social systems fully; treat structure and culture as being the same order of generality; and fail to recognize that these two orders of social facts need to be treated within different frames of reference (Smith 1971:231-32).

Hewlett (1991)also points out that most child development studies emphasize the child's relationships with members of the nuclear family, such as the mother, father, and siblings. That perspective, he contends, may 
reflect a European proclivity toward the nuclear family. Since the 1970s, however, many North American and Caribbean female scholars have examined women's choices as part of the "adaptive responses" approach which does not necessarily presume the nuclear family as normative (Chant 1997).

This recent literature has observed the influences of women migration and of childcare patterns. Evans and Davies's(1997) for example look comprehensively at the domestic, political, economic contributions of Jamaican women and childhood socialization. Hewlett's (1991)crosscultural anthropological study of demography and childcare in pre-industrial societies shows that although many anthropologists have been interested in the relationship between demography and cultural factors (Caldwell, Caldwell and Caldwell 1987; Hammel and Howell 1987), few studies have linked population demography to childcare patterns (LeVine 1974; Alcorta 1982).

There we see Hewlett (1991:2) emphasizing the connection with cross-cultural qualitative study of childcare that was pioneered by the Whitings (1975) and others(LeVine and LeVine 1966; Munroe and Monroe 1971; Mintern and Hitchcock 1966). Those remarkable studies of six cultures have provided the comparative methodology for 
socialization research in anthropology and have stimulated research on child development around the world (Ibid.: 1991).

Despite the recent development in the literature most studies, however, have not placed sufficient focus on the long term effects of the shifting of child rearing responsibilities from the birth mother or birth parents to other individuals within or external to the kinship network (Brodber 1975; Robert and Sinclair 1978). 


\section{CHAPTER IV. \\ SUMMARY AND CONCLUSIONS}

The recurring theme that has remained in the Caribbean family literature is the great flexibility and resiliency in Jamaican family household units (Beckford and Witter 1980). The matrifocal family forms are identified as key indicators of the resiliency and flexibility of families in Jamaica(Patterson 1982). The literature credits three elements for contributing to the resiliency of the Jamaican family over time (Patterson 1982; Barrow 1996, Roberts and Sinclair 1978). These elements are the flexibility of the two roles women play as laborers and as the heads of households (Roberts and Sinclair: 161), as well as the acceptance of the practice of child shifting (Gordon $1996: 106)$.

Women of matrifocal units in Jamaica, are portrayed as overburdened in performing all household chores, supplying economic provision, and being responsible for the socialization of the children (Chant 1997). Rodman (1971) identified child shifting as an integral part of the elastic or adaptive strategy that functions as part of the flexibility of household composition in the Caribbean. It is in that sense that child shifting fits within the 
"adaptive responses" approach as an alternative household level economic strategy.

The finding of this study is that while there may be some compensation involved in combining resources or manipulating the numbers of dependent children within households in Jamaica(Gordon 1987), when the shifting arrangement are within unsatisfactory environments the effects on the child can be very damaging(Evans and Davies 1997; Crawford-Brown 1993; Barrow 1996:407). As indicated in several studies, while the treatment of shifted children may vary in Jamaica, there are many adjustment problems for children relating to abandonment, anxiety, loss, and difficulty trusting after the shifting experience(Evans and Davies 1997; Leo-Rhynie 1993). Leo-Rhynie (1993) cautions that maternal deprivation of any kind, particularly in early childhood may result in delays in social, physical, and intellectual development.

In comparing the cultural diffusion, social pathology and the structural functionalism "adaptive responses" paradigms, we find the latter more applicable in analyzing both matrifocality and child shifting in Jamaica. The historical contribution of the cultural diffusion paradigm should not, however, be overlooked. The "adaptive responses" approach within, the structural functionalism 
paradigm, with emphasis on the impact of economic and gender disparity, provides a suitable framework for understanding the development of Jamaican family structures.

The concerns raised by Ennew's study (1982:560) and the stories introduced as anecdotal information in this study suggest that there may be many aspects to child shifting that are yet to be analyzed. For example, there is a profound need for more anthropological research concerning children's perspectives of child shifting.

Essential to such analysis is the understanding of the "adaptive responses" approach and its usefulness in explaining how the matrifocal family functions within a patrilineal society such as Jamaica (Clarke 1966). As for theoretical and policy implications, insufficient data have been gathered about the three forms of child shifting (i.e. historical, current incoming, current outgoing) identified by Gordon (1996) to provide specific policy guidelines. The consensus in the literature is that the number of matrifocal households (Chant 1997: 268) and subsequent incidences of child shifting will continue to increase (Roberts and Sinclair 1978; Barrow 1996). Therefore it is imperative that more ethnographic data is gathered about child shifting. 
In considering Blumberg and Garcia's (1977) study that shows a direct relationship between family structures, childcare practices and society's political economy, clearly it is important to further assess policies, theoretical approaches, and interventions that might enhance family resiliency especially within the low-income earning sectors in Jamaica. 
Alcorta, C. (1982) Parental Behavior and Group Competition. Behavior Science Research 17:3-23.

Barrow, Christine (1986). Finding the support: A Study of Strategies for Survival. Social and Economic studies, 35:2, 131-76.

(1996) Caribbean Family Studies: Ian Randle Publishers Ltd. Kingston, Jamaica.

Beckford, G. and Witter, M. (1980) Small Garden-Bitter Weed. University of the West Indies, Mona: Maroon Publishers.

Besson, Jean (1993) Reputation \& Respectability Reconsidered: A New Perspective on Afro-Caribbean Peasant Women in Jamaica. Women \& Change in the Caribbean.

Blake, Judith, Blumberg, R., Lesser, Garcia. (1961) Family Structure in Jamaica, New York.

Blumberg, R. L. and Garcia M. Pilar (1977) The Political Economy of the Mother-Child Family In Beyond the Nuclear Family Model: Cross-Cultural Perspective, London.

Bolles, L. (1996) Sister Jamaica: A Study of Women, Work and Households in Kingston. University Press of America New York.

Bowlby, I. (1969) Attachment and loss. New York: Basic Books

Brereton, B. (1974) ' The Experience of Indentureship: 1845-1917'. In J. LaGuerre (ed.) Calcutta to Caroni: The East Indians of Trinidad. London, Longman Caribbean Ltd, 25-38.

Brodber, E. (1974) Abandonment of Children in Jamaica. University of the West Indies, Kingston: ISER, Mona, Jamaica.

(1982) 'The Perceptions of Caribbean Women.' Cave Hill, Barbados: Institute for Social and Economic Research. 
(1986) Afro-Jamaican women at the turn of the Century. Social and economic Studies, 35, 23-50.

Caldwell, J., P. Caldwell, and B. Caldwell, (1987) Anthropology and Demography. Current Anthropology 28 (1): 25-34.

Chant, S. (1997) Woman-Headed households: Macmillan Press London.

Clarke, E. (1957) My Mother Who Fathered Me: A study of the family in three selected communities in Jamaica, Allen \& Unwin, London.

Crawford-Brown, C. (1997) The Impact of Parent-Child Socialization on The development of Conduct Disorder in Jamaican Male Adolescents. Caribbean Families: Diversity Among Ethnic Groups Ablex Publishing Corp Greenwich, Conn.

Dechesnay, M. (1986) Jamaican Family Structure: The Paradox of Normalcy. Family Process Inc.:25, 293-300.

Durant-Gonzalez, Victoria. (1982) The Realm of Female Familial Responsibility. In Joycelin Massey (ed) Women and The Family, pp. 1-27. Cave Hill, Barbados: University of The West Indies, Institute of Social and Economic Research.

Ennew, J. and Young, P. (1981) Child Employment in Jamaica (London: Anti-Slavery Society, Child Labour Series No. 6).

Ennew, J.(1982) Family Structures, Unemployment and Child Labour in Jamaica, Development and Change, 13 551-63

Evans, H. and Davies R. (1997) In Roopnarine J. And Brown's J. Caribbean Families: Diversity Among Ethnic Groups Ablex Publishing Corp. Greenwich Conn.

Evans, H. (1996) Perspective on the Socialization of the Working-Class Jamaican Child. Social and Economic Studies, Vol. 38, No. 3.

Fortes, M. (1947) In Smith, R. T. (1973) The Matrifocal 
family. The Character of Kinship. Cambridge University Press.

(1943) A Note on Fertility among the Tallensi of the Gold Coast. Sociological Review 35:99-113.

Frazier, F. (1939) The Negro Family in the United States. Chicago: University of Chicago Press.

Gonzales, N. (1970) Towards a Definition of Matrifocality. In N. E. Whitten and J. F. Szwed (eds.) Afro-American Anthropology, New York: The Free Press, 32144 .

Gordon, S. (1987) 'I Go to 'Tanties': In Barrow, C., (1996) Caribbean Family Studies: Ian Randle Publishers Ltd. Kingston, Jamaica.

(1996) 'I Go to 'Tanties' In Barrow, Christine Caribbean Family Studies: Ian Randle Publishers Ltd. Kingston, Jamaica.

Grant, D. (1974) Living Conditions of Some Basic School Children: Pointers to Disadvantage, Kingston: PECE

Gussler, J.(1980) 'Adaptive Strategies and Social Networks of Women in St. Kitts'. In Bourguignon (ed) A World of Women: Anthropological Studies of Women in the Societies of the World. New York, Praeger.

Hall, R (1979) Backyard Nurseries day care: The People's way. Torch, 26 (2).

Hammel, E. A., and N. Howell( 1987) Research in Population and Culture: An Evolutionary Framework. Current Anthropology 28: 141-60.

Henriques, F. (1953) Family and in Jamaica, Eyre and spottiswoode.

Henslin, J. M. (1985) Marriage and Family in a Changing Society, Collier Macmillian Canada, Inc.

Herskovits, M. (1941) Myth of the Negro Past, New York. 
Harper Bros.

Herskovits M. and Herskovits F. (1947) Trinidad Village. New York, Alfred A. Knopf.

Hewlett, Barry (1991) Demography and Childcare in Preindustrial Societies. Journal of Anthropological Research (Formerly Southwestern Journal of Anthropology) vol. 47 No. 1 .

Higman, B. (1973) 'Household Structure and Fertility on Jamaican Slave Plantation: a Nineteenth Century Example', Population Studies, 27, 3, 527 - 550 .

Kerr, M. (1952) Personality and Conflict in Jamaica, Collins, London.

1963. Personality and Conflict in Jamaica. London: Collins

Khun, T. (1970) The structure of Scientific Revolutions. Chicago: The University Press of Chicago. In professional Development: The international Journal of Continuing Social Work Education Vol. 1 No. 1 Sp. 1998.

Leo-Rhynie, E. (1993) The Jamaican Family: Continuity and Change. Grace Kennedy Foundation Lecture, Kingston Jamaica.

LeVine, R. A. (1974) Parental Goals: A Cross-Cultural View. Teachers College Record 76(2): 226-39. New York Teachers College, Columbia University, New York.

Macionis, J. (1997) Society: the Basic. $4^{\text {th }}$ Ed. Prentice $\mathrm{Hall}$.

Malinowski, B. (1944) A Scientific Theory of Culture and Other Essays. Chapel Hill: University of North Carolina Press.

(1945) The Dynamics of Cultural Change. New Haven: Yale University Press. 
Mintz, S. and Price, R. (1976) An Anthropological Approach to the African American Past: A Caribbean Perspective, Philadelphia Institute for the study of Human Issues.

Mohammed, P. (1986) Caribbean Family Revisited: In Women and Development Studies Project.

Murdock, G. (1949) Social Structure. New York. The Free Press.

Parson, T. (1951) The Social System. Glencoe, Illinois: The Free Press.

Parson and Bales. (1955) " The American Family." In Family Socialization and Interaction Process. Glencoe. The Free Press.

Patterson. O., (1982) Persistence, Continuity and Changes in the Jamaican Working-Class Family. Journal of Family History, Sum. 1982, p.135-161.

Patterson. O.,(1982)) Slavery and Social Death. Harvard University Press, Cambridge, Mass.

Powell, D., (1982) Network Analysis: A Suggested Model for the study of Women and the Family in the Caribbean. In Joycelin Massey (ed). Women and The Family, pp. 1-27. Cave Hill, Barbados: University of The West Indies, Institute of Social and Economic Research.

Prior, M. (1993) Matrifocality, Power, and Gender Relations in Jamaica.

Radcliffe-Brown, A. R. (1965) structure Function in Primitive Society: Essay and Addresses. New York:

The Free Press.

Robert, G. (1975) Fertility and Mating in Four west Indian Populations. Jamaica, University of the West Indies, Institute of Social and Economic Research.

Roberts, G. W. and Sinclair. (1978) Women in Jamaica: 
Patterns of Reproduction and Family, Millwood New York, KYO Press.

Rodman, Hyman (1971) Lower Class Families: The Culture of Poverty in Negro Trinidad, New York: Oxford Press.

Roopnarine, J. And Brown, J (1997) Caribbean Families: Diversity Among Ethnic Groups Ablex Publishing Corp. Greenwich Conn.

Russell-Brown, P, Norville, B. and Griffith, C. (1997) Child Shifting: A Survival strategy for Teen Mothers In Caribbean Families: Diversity Among Ethnic Groups Ablex Publishing Corp. Greenwich Conn.

Safa, H. and Antrobus, P. (1992) 'Women and the Economic Crisis in the Caribbean', in Lourdes Beneria and Shelley Feldman (eds), unequal Burden: Economic Crises, Persistent poverty and Women's Work (Boulder, Colordo: Westview Press) 49-82.

Senior, O. (1991) Working Miracles: Women's Lives in the English Speaking Caribbean. Institute of Social and Economic Research (Eastern Caribbean), Barbados, University of the West Indies.

Simey, T., (1946) Welfare Planning in the West Indies. Oxford: Clarendon Press.

Smith, M. G. (1962) West Indian Family Structures, Seattle: University of Washington Press.

(1957) The African Heritage in the Caribbean. In V. Rubin (ed) Caribbean Studies : A Symposium. Jamaica, Institute of Social and Economic Research, University College of The West Indies, 34-46.

(1965) The Plural Society in the British West Indies, University of California Press.

(1966) Introduction In Edith Clarke, My Mother Who Fathered Me, London: George Allen \& Unwin. 
Smith, R. T. (1956) The Negro Family in British Guiana. London, Routledge and Kegan Paul.

(1973) The Matrifocal family. In J, Goody (ed.) The Character of Kinship. Cambridge University Press.

(1982) Family, Social Change and Social Policy in the West Indies Nieve West Indies Gids, 56, $111-142$.

Sobo, E.J. (1996) Abortion in Rural Jamaican Social Science and Medicine. 42 No 4 p. 495-508.

STATIN. (1988) (Statistical Institute of Jamaica). Pocket of Statistics, Jamaica 1988. Statistical Institute of Jamaica, 1988.)

Stolcke, V. (1992) "The slavery Period and its Influence on Household structure and the Family in Jamaica, Cuba, Brazil", In Elza Berquo and Peter Xenox (eds.), Family Systems and Cultural Change (Oxford: Clarendon Press) $125-42$.

United Nations (UN). (1991) The World's Women 19701990: Trends and Statistics (New York: UN).

Whitehead, T. (1978) Residence, Kinship and Mating as Survival Strategies: A West Indian Example. Journal of Marriage and Family.

Whitten, N. and Szwed (1970) Strategies of Adaptive Mobility in the Columbian-Ecuadorian Littoral. In AfroAmerican Anthropology, Norman Whitten and John Szwed, eds. New York: The Free Press. 